\title{
A rare cause of shoulder pain: axillary web syndrome
}

\author{
Yasin Demir, Ümüt Güzelküçük, Serdar Kesikburun, Evren Yaşar, Arif Kenan Tan \\ Department of Physical Medicine and Rehabilitation, Gülhane Military Medical Academy, Turkish Armed Forces Rehabilitation Center, Ankara, Turkey
}

Received: December 2014 Accepted: April 2015

\begin{abstract}
A 40-year-old male patient was admitted with complaints of right shoulder pain and decreased range of motion for two days. He was diagnosed with axillary web syndrome. Palpable subcutaneous cord which extended from axillary crease down to the ipsilateral arm was revealed. He was administered a non-steroidal anti-inflammatory drug and arranged 15 sessions of physical therapy. To the best of our knowledge, this is the first case to be reported in the literature without any known etiology, and we call attention of clinicians to this syndrome.
\end{abstract}

Keywords: Axillary web syndrome; pain; physical therapy.

Axillary web syndrome (AWS), which is also known as axillary cording, is a clinical entity defined as prominent palpable subcutaneous tissue extending from the axilla into the medial elbow, even down to the medial part of the wrist. ${ }^{[1]}$ It can limit the range of motion (ROM) of the shoulder, particularly in abduction. It may be more prominent and painful with shoulder abduction.

There is uncertainty in the literature on its pathogenesis. This disorder usually occurs one to five weeks after axillary surgery. ${ }^{[2]}$ To date, no specific therapy regimen has been proven effective in changing progress. Herein, we report a case of AWS without a known etiology in whom the complaints resolved within a month.

\section{CASE REPORT}

A 40-year-old man was admitted to our clinic with complaints of right shoulder pain and decreased ROM for two days. He had no medical or surgical history. On physical examination, shoulder abduction and flexion were measured as $140^{\circ}$ and $150^{\circ}$, respectively. No erythema, warmth or any other inflammatory signs were observed in the axillary region. A palpable subcutaneous cord which extended from the axillary crease down to the ipsilateral arm was inspected
(Figure 1). His Visual Analog Scale (VAS)-pain score was 8. Neurological examination, Doppler ultrasound of the axillary vein, and axillary magnetic resonance imaging findings were normal. Erythrocyte sedimentation rate, C-reactive protein, and complete blood count tests to detect any possible infections or other inflammatory conditions were also normal. A written informed consent was obtained from the patient.

The patient was diagnosed with AWS and was administered $75 \mathrm{mg}$ naproxen sodium twice a day for seven days for pain relief, and 15 sessions of physical therapy were planned to include hot pack, ROM exercises, strengthening exercises of the shoulder girdle muscles to maintain correct shoulder biomechanics, stretching exercises for shoulder abduction and flexion and axillary myofascial release massage to resolve the cord and to increase venous and lymphatic drainage. At one month, the shoulder pain score was measured as 2 using the VAS, and the patient was able to achieve full ROM, while the cord disappeared (Figure 2).

\section{DISCUSSION}

Axillary web syndrome is likely to be associated with axillary surgery (either axillary lymph node or sentinel lymph node dissection) in breast cancer. ${ }^{[3]}$ It has been detected in $20 \%$ of patients with a sentinel

Corresponding author: Yasin Demir, MD. Gülhane Askeri Tıp Akademisi, Fiziksel Tıp ve Rehabilitasyon Anabilim Dalı, TSK Rehabilitasyon Merkezi, 06800 Çankaya, Ankara, Turkey. e-mail: dr_yasindemir@yahoo.com 


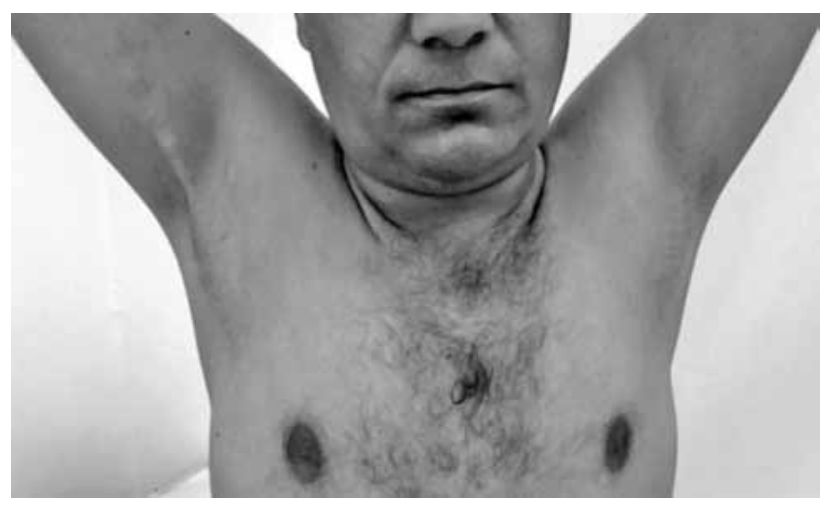

Figure 1. An axillary cord before treatment.

node biopsy and in $72 \%$ of patients with an axillary clearance. ${ }^{[3]}$ There are only two reported cases where AWS developed in patients without breast cancer: one was secondary to axillary folliculitis, and the other developed following a sentinel node biopsy for melanoma. ${ }^{[4,5]}$ No cause such as axillary intervention or folliculitis was present in the presented case, and it is considered that the AWS could have originated from small lymphadenopathies, which were not detectable with screening methods, leading to lymphatic obstruction.

The mechanism of AWS is not well-defined. It has been assumed that lymphovenous injury, hypercoagulation, lymphovenous stasis, and damage to tissues as a result of interrupted lymphatic and vascular flow caused by axillary surgery may gi§ve rise to the condition. ${ }^{[1]}$ In addition, Mondor's disease (MD), which is a rare entity involving thrombophlebitis of the superficial veins of the axilla, should be kept in mind in the differential diagnosis of AWS. Although it was also termed AWS previously, currently, both are accepted as different conditions. ${ }^{[4]}$ In our case, MD was ruled out due to normal venous flow during Doppler ultrasound.

Pain, which is the major symptom of this entity, can be felt in the shoulder or axilla. It limits the ROM of the shoulder with numbness and tightness. In addition, AWS-related shoulder ROM restrictions can lead to painful conditions, such as rotator cuff disease, frozen shoulder, and myofascial pain syndrome. ${ }^{[1]}$ Although the cord is visible in the axillary region, it can be neglected, if the patient is not undressed during the physical examination.

No standard therapeutic methods have been reported for AWS. Untreated AWS usually, but not always, disappears spontaneously within three

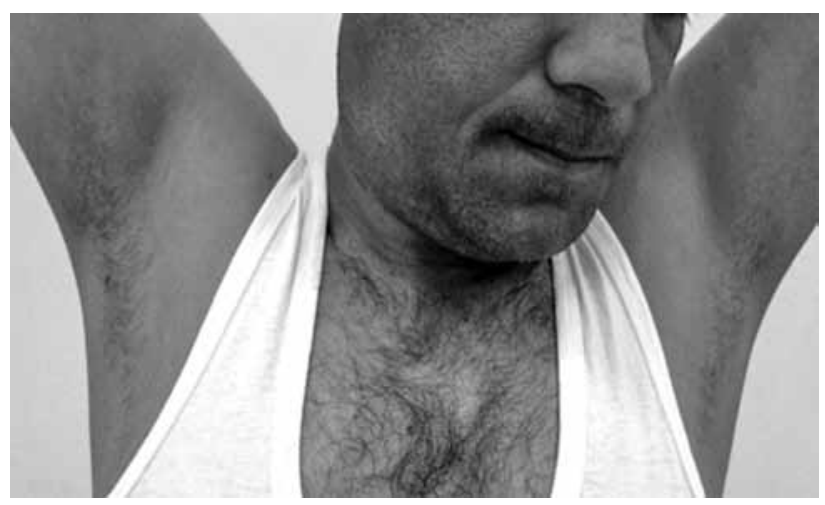

Figure 2. Cord disappeared after treatment.

months. ${ }^{[6]}$ Wei et al. ${ }^{[7]}$ suggested that Aescuven forte (Cesra Arzneimittel GmbH \&. Co. KG, Baden-Baden, Germany), which was used to treat phlebitis in their clinic, might be effective in improving AWS in combination with physical therapy. In the presented case, the symptoms relieved and the cord resolved within one month. This can be attributed to the medical treatment prescribed and physiotherapy applied, although whether it was routine progression or the treatment was effective still remains unclear. Therefore, further studies are required to provide more clinical data to study the treatment of AWS.

In conclusion, AWS may develop even without axillary surgery. Physical examination is the mainstay in the diagnosis of AWS, and examination of the axillary region should not be ignored in patients with shoulder pain and limited ROM. Patients with AWS may benefit from physical therapy fortified with non-steroidal antiinflammatory drugs. To the best of our knowledge, this is the first case to be reported in the literature without any known etiology, and we call attention of clinicians to this syndrome. However, there is a long way to go to clarify the pathogenesis and histopathology, and to develop effective treatments of AWS.

\section{Declaration of conflicting interests}

The authors declared no conflicts of interest with respect to the authorship and/or publication of this article.

\section{Funding}

The authors received no financial support for the research and/or authorship of this article.

\section{REFERENCES}

1. Torres Lacomba M, Mayoral Del Moral O, Coperias Zazo JL, Yuste Sánchez MJ, Ferrandez JC, Zapico Goñi A. Axillary web syndrome after axillary dissection in breast cancer: a prospective study. Breast Cancer Res Treat 2009;117:625-30. 
2. Moskovitz AH, Anderson BO, Yeung RS, Byrd DR, Lawton TJ, Moe RE. Axillary web syndrome after axillary dissection. Am J Surg 2001;181:434-9.

3. Leidenius $M$, Leppänen $E$, Krogerus L, von Smitten K. Motion restriction and axillary web syndrome after sentinel node biopsy and axillary clearance in breast cancer. Am J Surg 2003;185:127-30.

4. Rashtak S, Gamble GL, Gibson LE, Pittelkow MR. From furuncle to axillary web syndrome: shedding light on histopathology and pathogenesis. Dermatology
2012;224:110-4.

5. Clarke SA, Mortimer P, Powell BW. Axillary web syndrome following sentinel node biopsy for melanoma. J Plast Reconstr Aesthet Surg 2013;66:1810-1.

6. Cheville AL, Tchou J. Barriers to rehabilitation following surgery for primary breast cancer. J Surg Oncol 2007;95:409-18.

7. Wei P, Zhu L, Chen K, Jia W, Hu Y, Su F. Axillary web syndrome following secondary breast-conserving surgery: a case report. World J Surg Oncol 2013;11:8. 